\title{
New Formulations of Glass Based on Moroccan Natural Phosphate
}

\author{
A. NADIRI ${ }^{1}$, D. DHIBA ${ }^{2}$, A. BENTAYEB ${ }^{1}$, L. BIH ${ }^{3}$, J. MAGHNOUJ ${ }^{2}$ \\ ${ }^{1}$ UFR Sciences des Matériaux Inorganiques, Faculté des Sciences, Université Moulay Ismaïl, BP 4010, \\ Beni M'hamed, 50000 Meknès, Morocco. \\ ${ }^{2}$ Centre d'Etudes et de Recherches des Phosphates Minéraux (CERPHOS-OCP), 73 Bd My Ismaïl, \\ Casablanca, Morocco. \\ ${ }^{3}$ Laboratoire de Physico-Chimie des Matériaux, FST-Errachidia, BP 509 Boutalamine, Morocco.
}

\begin{abstract}
A range of opal or transparent porous phosphosilicate glasses have been prepared by quenching melted mixtures of Moroccan natural phosphate, diatomite and/or dolomie. Their physical and chemical properties such as density, glass transition temperature, thermal expansion coefficient and chemical durability are studied upon the chemical composition. Adding dolomite to an opal glass favors the elaboration of transparency one, increases the glass transition $\mathrm{Tg}$, reduces thermal expansion and improves the chemical durability.
\end{abstract}

\section{INTRODUCTION}

Phosphate glasses usually possess low melting temperature $\left(<1000{ }^{\circ} \mathrm{C}\right)[1-4]$, have high thermal expansion coefficients (in the range of $90-250 \times 10^{-7} /{ }^{\circ} \mathrm{C}$ ) $[2-4]$ and are of increasing interest for many applications such as optical fibers [5], electrolytes for high-energy density batteries [6] and medical domain [7]. In the past, their use had been limited by their relatively poor chemical durability [8]. Different efforts have been made to increase the chemical durability of phosphate glasses, but improvements are normally accompanied by an increased glass transition temperature $\mathrm{Tg}[9,10]$. It would be beneficial to produce a glass with both good durability and physico-chemical properties similar to that of their silicate counterparts.

The phosphosilicate system is of importance due to the similitude of $\mathrm{P}$ and $\mathrm{Si}$ coordinence. Phosphates and silicates exhibit similar crystalline structures based on $\mathrm{PO}_{4}{ }^{3-}$ or $\mathrm{SiO}_{4}{ }^{4-}$ tetrahedral units. Many works have been devoted to the synthesis and characterization of phosphosilicate compounds, most of them concerning the study of these systems in the glassy state $[8,9]$. The classical way to synthesize this class of materials consists of heating the solid reagents together until they melt. Unfortunately, this synthetic route requires high temperatures and does not favor high specific surface areas, since the reaction occurs through a liquid state. A way of avoiding these disadvantages is to use another method of synthesis or to use starting products allowing profit energetic and fused mixtures at low temperatures. The use of Moroccan natural materials such as phosphate, diatomite and dolomie, for the manufacture of glasses, seems to us a promising domain to prospect. 
The purpose of the present work is to investigate the chemical and physical properties of phosphosilicate glasses based on Moroccan phosphate [11]. It includes the physico-chemical characterization of phosphate, diatomite and dolomie materials used in the elaboration of the glasses.

\section{EXPERIMENTAL}

\section{Raw materials}

Phosphosilicate glasses, subject of this study, were elaborated using two or three natural raw materials of Moroccan origin (phosphate, diatomite and dolomite). The quality of these materials was analysed using several techniques. The products used as fluxes are $\mathrm{Na}_{2} \mathrm{CO}_{3}$ (99\%, Merck) and $\mathrm{K}_{2} \mathrm{CO}_{3}(99.5 \%$, Merck).

\section{Glass preparation}

The synthesis of glasses was carried out by traditional method, i.e. by solid route. After having treated and having crushed separately each raw material, those are mixed in suitable proportions [11]. The homogeneous mixture thus obtained, placed in a platinum crucible, is introduced into an electric furnace preheated at $900{ }^{\circ} \mathrm{C}$ for about $1 \mathrm{~h}$. Then, the mixture is heated gradually until total fusion (about $1250-1350{ }^{\circ} \mathrm{C}$ ). The molten mixture remained at this temperature for a certain time for refining. Molten glass is then cast into a $200{ }^{\circ} \mathrm{C}$ preheated silica capsule mold and annealed at $250{ }^{\circ} \mathrm{C}$ for few hours. The glass samples were kept in a desiccator to prevent possible reaction with air moisture.

\section{Characterization techniques}

X-ray diffraction (XRD) patterns of the samples in the form of powder were obtained using diffractometer working with $\mathrm{Cu}-\mathrm{K} \alpha$ radiation. A structureless spectrum should be obtained for an amorphous sample. Scanning electron microscopy (SEM) analyses were performed. The examinations are carried out on powders deposited on a conducting sheet of carbon. EDX detector of $x$-rays emitted by material allows, in addition to the chemical microanalysis of the elements, to obtain the electronic image. The whole chemical compositions of the raw materials and of the elaborate glasses have been determined by X-fluorescence. The glass density was measured by an Archimedes technique for which deionized water was used as the working fluid. The glass transition temperatures $(\mathrm{Tg})$ were determined using a heating rate of $10{ }^{\circ} \mathrm{C} / \mathrm{min}$. The thermal expansion coefficients $(\alpha)$ were measured by a dilatometer in air with a heating rate of $5{ }^{\circ} \mathrm{C} / \mathrm{min}$, where $\alpha$ value was determined from the temperature range [20 $600{ }^{\circ} \mathrm{C}$ ]. The tests of resistance to the glass chemical durability were carried out using weight loss method. The weight loss in aqueous solution, $\mathrm{HCl}$ or $\mathrm{NaOH}$, at different concentrations was estimated by weighing the dry samples before and after immersion; that losses are measured according to time.

\section{RESULTS AND DISCUSSION}

\section{Raw material characterization}

A better comprehension of the properties of elaborated glasses requires a good physicochemical characterization of the starting products used in their development.

$\mathrm{X}$-ray analysis of natural phosphates showed that they are primarily made of carbonated fluorapatite-type phase and by other minor additional minerals (quartz, calcite,...). On the spectra of samples treated at $1000{ }^{\circ} \mathrm{C}$ during $1 \mathrm{~h}$, it is noted that only the lines characteristic of the stoichiometric fluorapatite-type phase are present (Figure 1). 


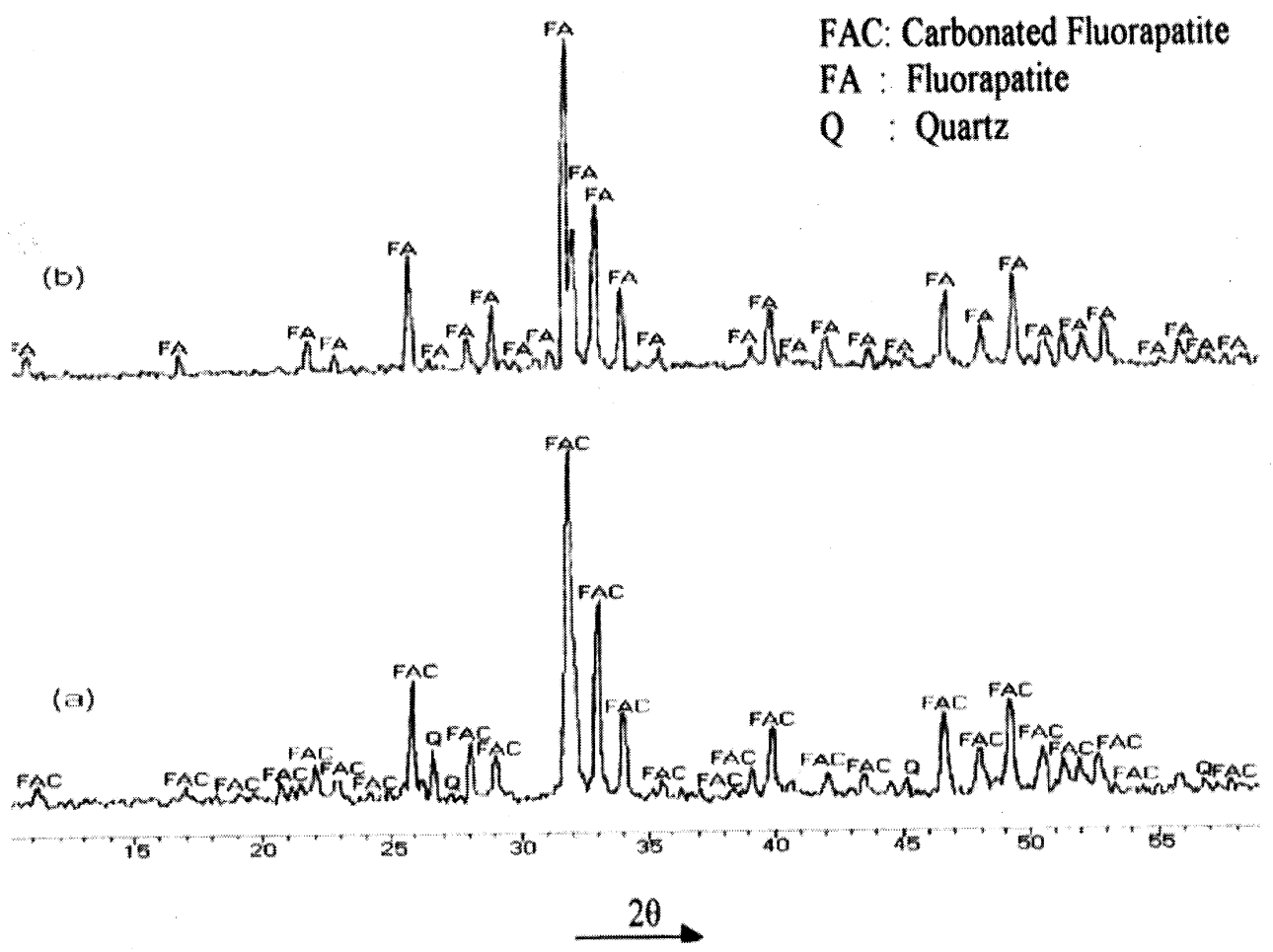

Figure 1: X-ray diffraction of Moroccan natural phosphate

(a): Raw material (b): After $1000^{\circ} \mathrm{C}$ heat-treatment

The chemical composition of the studied phosphates is determined. Its most important constituents are given in Table 1.

Table 1: Chemical composition (\% wt) of Moroccan natural phosphate, diatomite and dolomie chosen in this study

\begin{tabular}{|l|l|l|l|l|l|l|l|l|l|l|l|}
\hline & $\mathbf{P}_{2} \mathbf{O}_{\mathbf{5}}$ & $\mathbf{S i O}_{2}$ & $\mathbf{C a O}$ & $\mathbf{M g O}$ & $\mathbf{N a}_{2} \mathbf{O}$ & $\mathbf{K}_{\mathbf{2}} \mathbf{O}$ & $\mathbf{A l}_{2} \mathbf{O}_{3}$ & $\mathbf{F}$ & $\mathbf{F}_{2} \mathbf{O}_{3}$ & $\mathbf{S O}_{3}$ & ${ }^{*} \mathbf{L}_{1000}{ }^{\circ} \mathbf{C}$ \\
\hline Phosphate & 36.36 & 4.09 & 53.69 & 0.12 & 0.27 & 0.08 & 0.39 & 4.33 & 0.14 & 0.53 & - \\
Diatomite & - & 87.71 & 0.40 & 0.40 & - & 0.58 & 3.66 & - & 1.31 & 0.23 & 5.70 \\
Dolomie & - & 0.01 & 36.75 & 25.76 & - & - & 0.13 & & 0.12 & 0.08 & 37.14 \\
\hline
\end{tabular}

${ }^{*} L_{1000}{ }^{\circ} \mathrm{c}$ : weight $\%$ loss at $1000^{\circ} \mathrm{C}$ 
One can easily observe that the ratio $\mathrm{R}=\mathrm{CaO} / \mathrm{P}_{2} \mathrm{O}_{5}$ is equal to 1.48 ; it is higher than that corresponding to the stoichiometric fluorapatite $(\mathrm{R}=1.31)$. This excess can be due to the substitution of $\mathrm{PO}_{4}{ }^{3-}$ anions by $\mathrm{CO}_{3}{ }^{2-}$ in apatite as well as to the presence of calcite in natural phosphate. The examination of this latter by means of SEM shows relatively homogeneous granulometry (Figure 2).

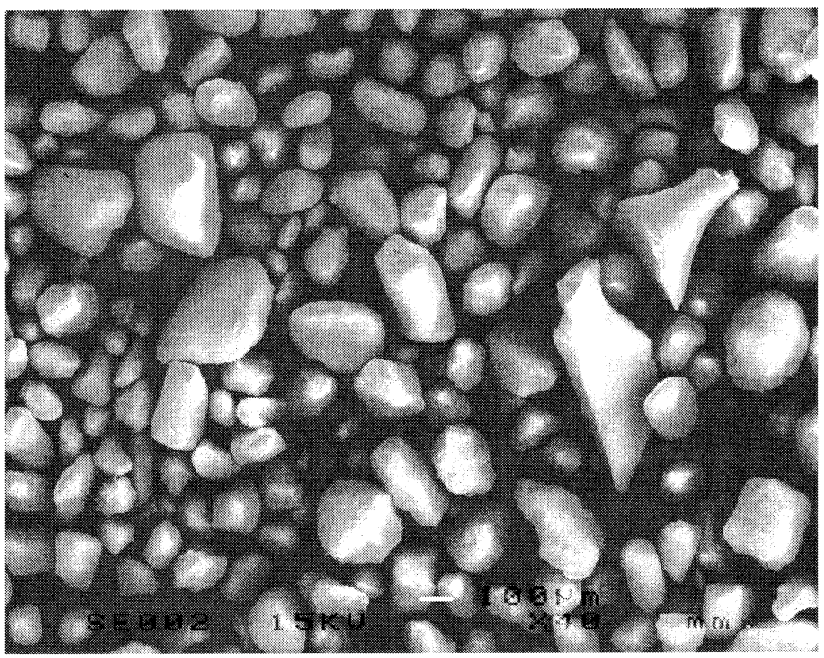

Figure 2: Scanning electron micrograph of Moroccan natural phosphate

Secondly, the diatomite used in the development of glasses was prone to several investigations in order to have some information about its structure and its morphology. The X-ray diffraction pattern recorded for the diatomite variety indicates that it is composed mainly of crystallized (quartz) or amorphous silica, which prevails. A minor phase of $\mathrm{CaCO}_{3}$ is also detected. The XRD pattern of the diatomite heat-treated at $1000{ }^{\circ} \mathrm{C}$ during $1 \mathrm{~h}$ shows the appearance of tridymite and quartz, but amorphous silica is the dominant (Figure 3). According to the quantitative analysis of this diatomite variety (Table 1), silica is the principal component of this material ( $87.71 \%$ weight).

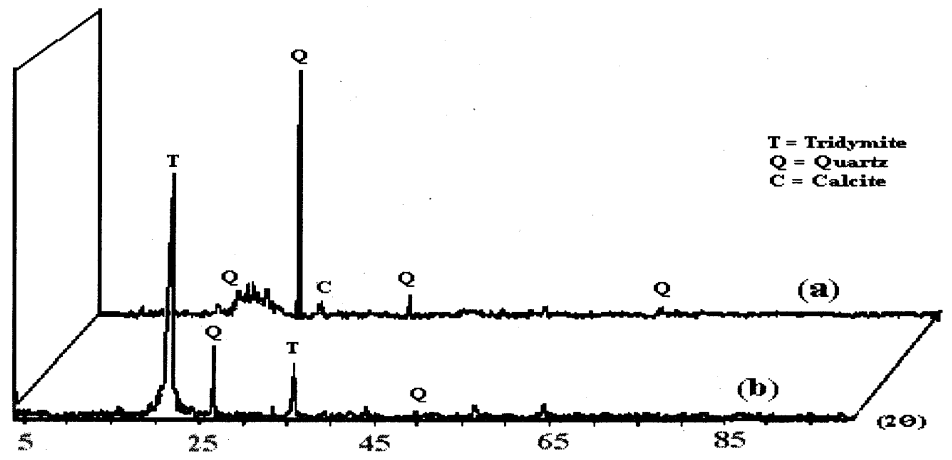

Figure 3: X-ray diffraction of Moroccan diatomite (a): Raw material (b): After $1000{ }^{\circ} \mathrm{C}$ heat-treatment 
Figure 4 shows the results of the examination of this variety by scanning electron microscopy. This morphological study reveals that the diatomite contains porous circular particles, with the interior of which are low-size pores. The analysis of the micrograph obtained after a heattreatment at $1100{ }^{\circ} \mathrm{C}$ during $1 \mathrm{~h}$ (Figure 4b), evidences a non change of the particle shapes. While basing itself on this analysis, one can expect that glasses worked out starting from this substance could be porous.
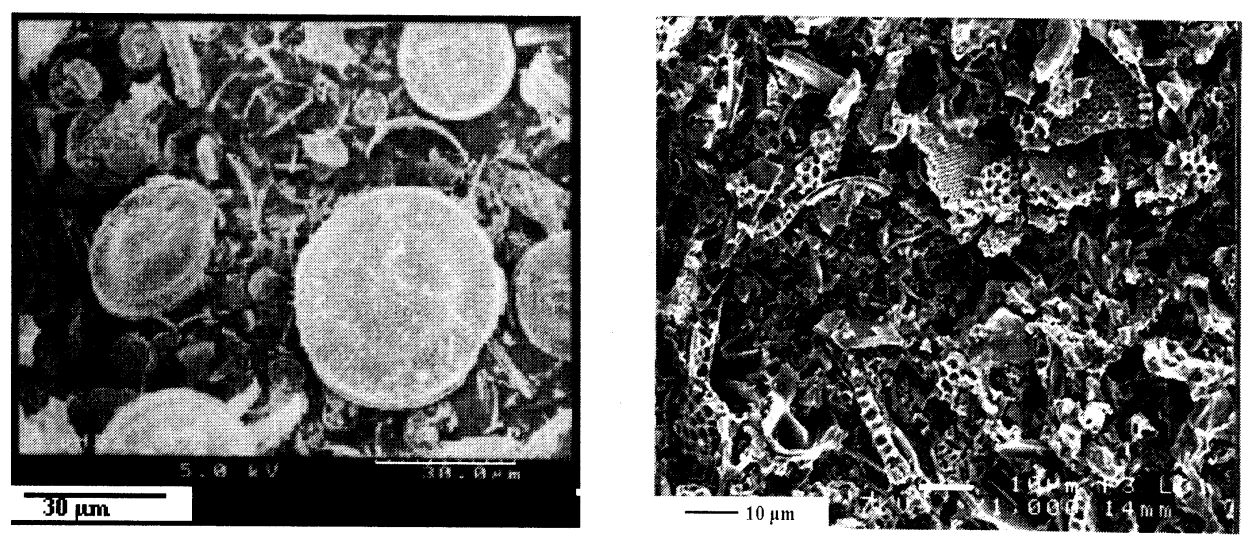

Figure 4: Scanning electron micrographs of Moroccan diatomite (a): Raw material (b): after $1100^{\circ} \mathrm{C}$ heat-treatment

Lastly, the results of the quantitative chemical analysis of the natural dolomie are shown in Table 1 . In the XRD pattern, we have detected only dolomie crystalline phase $(\mathrm{Ca}, \mathrm{Mg})\left(\mathrm{CO}_{3}\right)_{2}$ (Figure 5).

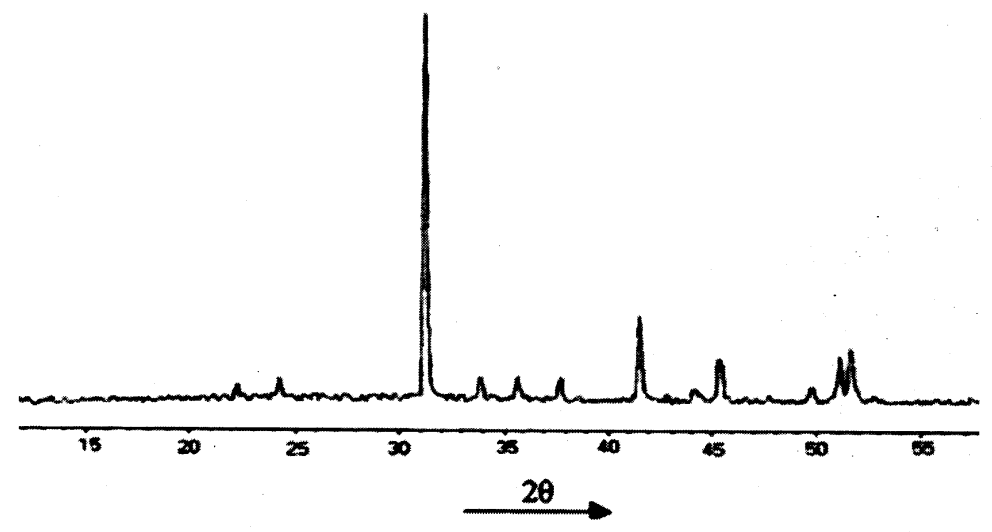

Figure 5: X-ray diffraction of Moroccan natural dolomie 
Referring to the dolomie chemical composition (Table 1), it is obvious that this material should ensure the introduction of alkaline-earth cations $\left(\mathrm{Ca}^{2+}, \mathrm{Mg}^{2+}\right)$ into the network of the elaborated glasses.

\section{Glass characterization}

The amorphous nature of the glasses is tested by X-ray diffraction and DTA analysis. All the as-prepared glasses have been found to be X-ray amorphous with a broad hallo in the XRD pattern. Among elaborate glasses, one can distinguish two groups according to the chemical composition: i) group 1- opal glasses obtained starting from phosphate and diatomite with carbonate fluxes; group 2-glasses containing dolomie in addition to the components of group 1. They are colored transparent glasses. From a chemical composition point of view, glasses belonging to group 1 are rich in alkaline elements and poor in alkaline-earth elements $(\sim 0 \%$ $\mathrm{MgO}$ ), those of group 2 show the reverse. The total mass concentration of oxides $\mathrm{Al}_{2} \mathrm{O}_{3}$ and $\mathrm{Fe}_{2} \mathrm{O}_{3}$ in such glass doesn't exceed 3\%. Table 2 shows the chemical compositions of two typical vitreous samples with a constant $\mathrm{O} /(\mathrm{Si}+\mathrm{P})$ ratio representative of opal and transparency groups.

Table 2: Glass composition in weight percentage and some of their physical properties

\begin{tabular}{|c|c|c|c|c|c|c|c|c|c|c|c|c|}
\hline Glass & $\mathbf{P}_{2} \mathbf{O}_{5}$ & $\mathrm{SiO}_{2}$ & $\mathrm{CaO}$ & MgO & $\mathrm{Na}_{2} \mathrm{O}$ & $\mathrm{K}_{2} \mathrm{O}$ & $\mathrm{Al}_{2} \mathrm{O}_{3}$ & $\mathrm{Fe}_{2} \mathrm{O}_{3}$ & d & $\begin{array}{c}\mathrm{Tg} \\
\left({ }^{\circ} \mathrm{C}\right)\end{array}$ & $\begin{array}{c}\alpha \\
\left(\times 10^{-6}\right. \\
\left.{ }^{\circ} C^{-1}\right)\end{array}$ & $\begin{array}{c}\mathrm{D}_{\mathrm{R}}(\mathrm{mg} / \\
\left(\mathrm{cm}^{2} . \text { day }\right)\end{array}$ \\
\hline opal & 12.60 & 48.86 & 20.60 & - & 11.06 & 5.53 & 2.00 & 0.97 & 1.67 & 322 & 2.71 & 2.05 \\
\hline trans. & 13.22 & 48.26 & 25.82 & 4.13 & 7.37 & - & 1.94 & 1.02 & 1.80 & 477 & 1.85 & 1.25 \\
\hline
\end{tabular}

In both groups 1 and 2, the densities of the glasses at room temperature increased generally with increasing $\mathrm{P}_{2} \mathrm{O}_{5}$ content. Also, as alkaline-earth $\left(\mathrm{Ca}^{2+}, \mathrm{Mg}^{2+}\right)$ ions were replaced by alkaline ions $\left(\mathrm{Na}^{+}, \mathrm{K}^{+}\right)$while keeping a constant $\mathrm{O} /(\mathrm{Si}+\mathrm{P})$ ratio, the densities generally decreased (Table 2). The decrease in the densities cannot be explained by a simple mechanism.

Differential thermal analysis performed on the glasses has confirmed their vitreous nature. It is observed that DTA diagrams show only the endothermic peak which is related to the glass transition temperature ( $\mathrm{Tg}$ ), but no crystallization peak is detected within the studied temperature range. Therefore, one can state that the thermal stability against crystallization of the elaborated glasses is considerably high. Table 2 shows also that the substitution of $(\mathrm{MgO}+\mathrm{CaO})$ for $\left(\mathrm{Na}_{2} \mathrm{O}+\mathrm{K}_{2} \mathrm{O}\right)$ by keeping the same $\mathrm{O} /(\mathrm{Si}+\mathrm{P})$ ratio reduces the Tg temperature. It indicates that $\mathrm{Tg}$ values are dependent of the change of dolomie content under a constant $\mathrm{O} / \mathrm{Si}+\mathrm{P}$ ratio. This decrease is believed to be due to the replacement of alkaline-earth elements with alkaline ions which decreases the cross-link density in the glass [12].

The thermal expansion coefficients $(\alpha)$ are performed on glasses using a dilatometer. The results obtained show that the $\alpha$ decrease with increasing of dolomie content as well as with decreasing alkaline content (Table 2). The higher the $\mathrm{MgO}$ content which depends on alkaline one, the lower the $\alpha$. This is mainly related to the fact that field strength of the $\mathrm{Na}^{+}$ion is lower than that of the alkaline-earth ion in the glasses. The increase in field strength of the cations in the glasses which results in a tighter network can be correlated with the deeper potential energy well resulting in a decrease of the anharmonic vibrations. A similar trend has 
been observed in other glass systems $[13,14]$. The rigidity of the network of higher field strength glasses accounts for the reduction in $\alpha$.

Chemical durability was measured as weight loss per unit surface area per unit time $\left(\mathrm{mg} \cdot \mathrm{cm}^{-2} \cdot \mathrm{day}^{-1}\right)$. Glasses reported in Table 2 were tested under the same conditions for comparison. The dissolution rates, $D_{R}$, (6 days) of the opal glass and the transparency one, estimated from their weight loss in alkaline solution $(3 \mathrm{~N})$ at room temperature, are $2.05 \pm 0.20\left(\mathrm{mg} . \mathrm{cm}^{-2}\right.$.day $\left.{ }^{-1}\right)$ and $1.25 \pm 0.15\left(\mathrm{mg}^{-\mathrm{cm}^{-2}}\right.$.day $\left.{ }^{-1}\right)$, respectively. Clearly, $\mathrm{D}_{\mathrm{R}}$ varies with dolomie $(\mathrm{MgO})$ content. Since the glasses (Table 2$)$ offer a constant $\mathrm{O} /(\mathrm{Si}+\mathrm{P})$ ratio and a constant $\left(\mathrm{Al}_{2} \mathrm{O}_{3}+\mathrm{Fe}_{2} \mathrm{O}_{3}\right)$ content, the increase of the dissolution rate from 1.25 for transparency glass to $2.05\left(\mathrm{mg}_{\mathrm{cm}} \mathrm{cm}^{-2}\right.$.day $\left.{ }^{-1}\right)$ for a opal glass, can be related to the increase of glass network rigidity with increasing $\mathrm{MgO}$ content. It is known that the cross-link density of pure anhydrous phosphate decreases when the mole percent of $\mathrm{P}_{2} \mathrm{O}_{5}$ decreases from $100 \%$ to 50\% [15]. The phosphate glasses are made up of polymeric phosphate anions which are connected to the modifying cations by ionic bonds. For such a structure, it is observed that other cations can serve as ionic cross-links between the non-bridging oxygens of the two different chains. Van Wazer et al. [16] have suggested that such a cross-linkage could take the form of a metal chelate structure. For colored transparent glasses containing $\mathrm{MgO}$ the bond strength is expected to increase compared to that of a opal glass (without $\mathrm{MgO})$, but having a constant $\mathrm{O} /(\mathrm{Si}+\mathrm{P})$ ratio. It is thus obvious that the colombic force between non-bridging oxygen and cation increases, bond strength is expected to increase, resulting in a greater chemical durability. We suggest also that the presence of oxides such as $\mathrm{Fe}_{2} \mathrm{O}_{3}, \mathrm{Al}_{2} \mathrm{O}_{3}$ in the structure of the studied glasses results in the formation of $\mathrm{P}-\mathrm{O}-\mathrm{Fe}$ and $\mathrm{P}-\mathrm{O}-\mathrm{Al}$ bonds and leads, along with $\mathrm{MgO}$, to improve their chemical durability. It should be noted also that the dissolution rates for the glasses studied decrease as the time of immersion in aqueous solution increases. In both glasses, it is observed that fast corrosion takes place in the beginning and slows down with time. Moreover, after chemical attack, the glass is surrounded by a white layer. Thus, the high chemical durability of these glasses could be due to the formation of the white protective coating which can be $\mathrm{Ca}(\mathrm{OH})_{2}$ and/or $\mathrm{Mg}(\mathrm{OH})_{2}$. In the early stages the aqueous solution is still dilute and the increase of glass leaching products has relatively minor effect upon the rate of dissolution reaction. As the reaction proceeds, the build-up of corrosion products in solution begins to affect the rate of glass reaction. Secondary phases precipitated on the glass surface can decrease the corrosion rate and inhibit mass transfer from the glass to solution [17-20].

SEM micrograhs obtained for both opal and transparent studied glasses are similar. Figure 6 shows a SEM photo of the opal glass in which the composition is given in Table2. It is noted that these glasses are porous, and the distribution and the size of the pores being statistical. Such porosity can be due to the use of the diatomite like primary product of the vitreous chemical compositions. On the basis of another diatomite variety, Xihuai [21] also worked out porous borosilicate glass. Indeed, using sol-gel method, the porous $\mathrm{P}_{2} \mathrm{O}_{5}-\mathrm{SiO}_{2}$ glasses were prepared by Nogami et al [22], and their pore properties were changed by controlling the preparation conditions. 


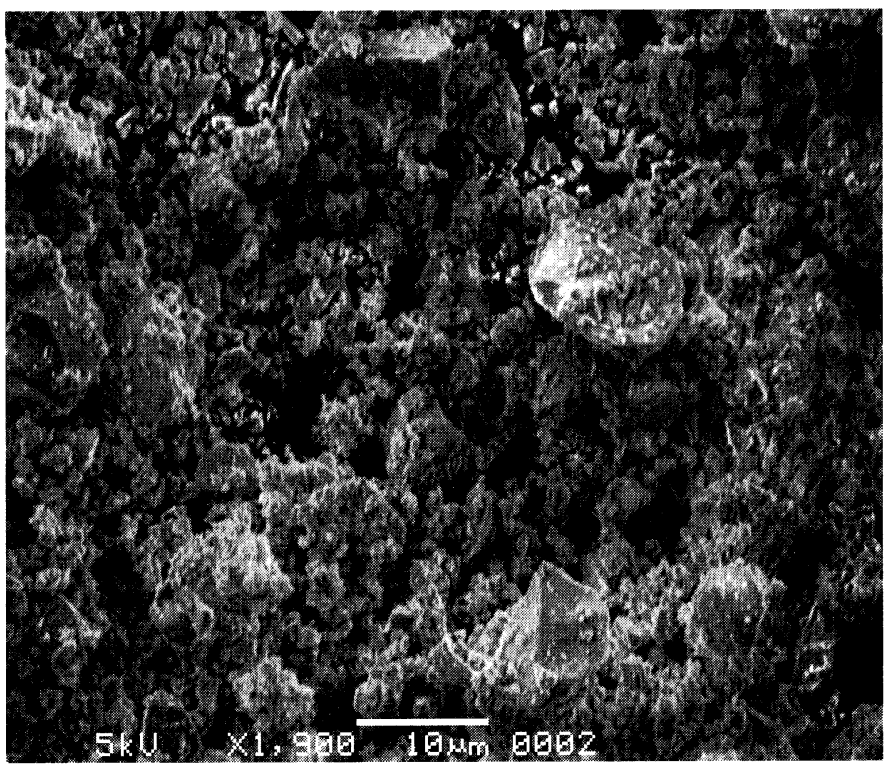

Figure 6: Scanning electron micrograph of the opal glass

\section{CONCLUSIONS}

Vitreous porous phosphosilicate can be obtained through solid state reaction using Moroccan natural phosphate, diatomite and dolomie. Opal glasses are elaborated using phosphate and diatomite materials. By adding the dolomie, colored transparent glasses are developed. The chemical durability of the glasses belonging to the latter group is better than that of the former one. The improved chemical durability and the decrease of the thermal expansion coefficient with increasing dolomie content is observed, and are ascribed to the bond strength in the glass matrix. The morphological porous form of the glasses is related to the presence of diatomite.

\section{REFERENCES}

1. P.A. Tick, Phys. Chem. Glasses, 25, 149 (1984).

2. C.M. Shaw, J.E. Shelby, Phys. Chem. Glasses, 29, 49 (1988).

3. Y. He, D.E. Day, Glass Technol., 33, 214 (1992).

4. H.S. Liu, P.Y. Shih, T.S. Chin, Phys. Chem. Glasses, 37, 227 (1996).

5. S.G. Kosinski, D.M. Krol, T.M. Duncan, D.C. Doglass, J.B.MacChesney, J.R. Simpson, J. Non-Cryst. Solids, 105, 129 (1988).

6. H.L. Tuller, D.P. Button, D.R. Uhlmann, J. Non-Cryst. Solids, 40, 45 (1980).

7. L.L. Hench, J. Am. Ceram. Soc., 74, 1487 (1991). 
8. R.C. Ropp, Inorganic Polymeric Glasses, Elsevier, New York, (1992).

9. J.T. Hunt, D.R. Speck, Opt. Eng., 28, 464 (1989).

10. J.H. Campell, T.I. Suratwala, J. Non-Cryst. Solids, 263-264, (2000) 318.

11. CERPHOS-OCP, Casablanca (Morocco), Patent PV Casa N²6726 PV Tanger $\mathrm{N}^{\circ} 2280$.

12. N.H. Ray, J. Non-Cryst. Solids, 15, (423 (1974).

13. J.A. Wilder, J.E. Shelby, J. Am. Ceram. Soc., 67, 438 (1984).

14. J.O. Byun, B.H. Kim, K.S. Hong, H.J. Jung, S.W. Lee, A.A. Izyneev, J. Non-Cryst. Solids, $\underline{190}, 288$ (1995).

15. B.C. Bunker, G.W. Arnald, J.A. Wilder, J. Non-Cryst. Solids, 64, 291 (1984).

16. J.R. Van Wazer, J. Am. Ceram. Soc., 72, 655 (1950).

17. X. Zhao, S. Sakka, Mat. Sci. Forum., 2267, 32 (1988).

18. B.C. Sales, L.A. Boatner, Mater. Lett., 2, 301 (1984).

19. D.E. Day, Z. Wu, C.S. Ray, P. Hrma, J. Non-Cryst. Solids, 241, 1 (1998).

20. S.T. Reis, M. Karabulut, D.E. Day, J. Non-Cryst. Solids, 292, 150 (2001).

21. H. Xihuai, J. Non-Cryst. Solids, 112, 58 (1989).

22. M. Nogami, R. Nagao, C. Wong, T. Kasuga, T. Hayakawa, J. Phys. Chem. B, 103, 9468 (1999). 